\title{
The Role of Principals and Administrators in Performance Appraisal of School
}

\section{Teachers in Punjab}

* Muhammad Nadeem, PhD Scholar (Corresponding Author)

** Dr. Seema Arif, Associate Professor

*** Dr. Muhammad Naeem

\begin{abstract}
Qualitative research was conducted in the interpretive paradigm using phenomenology as an approach to check the execution of the performance appraisal system (PAS) at higher secondary schools in Punjab. The population of the study consisted of key stakeholders of appraisal, higher secondary school principals, teachers, and district administration. 6 out of 36 districts were selected from school district rankings, each falling in poor, good, and average criterion. Participants of one district served as a pilot and the rest for the main study. A total of 35 participants were selected from five districts purposively; a selection criterion was used to select a set of one administrator, one principal and five teachers from each of the five districts. After obtaining consent from the participants, structured interviews were conducted with the school principals and district administrators, while the focus group was held with the teachers of each district using selfconstructed interview protocols. Thematic analysis was performed on data obtained from different sources. Seven themes emerged during analysis reflected that the principals and teachers have enough knowledge and experience to conduct the PAS. It is a positive activity that must be continued; however, the procedure needs improvement. PAS should be planned and conducted with the consultation of teachers, motivating them for further improvement.
\end{abstract}

Keywords: Performance Appraisal, Stakeholders, Satisfaction, Dissatisfaction, Professional Introduction Development

Performance Appraisal System (PAS) is a phenomenon in which the manager or supervisor analyses an employee's job performance; as a result, the employee is given either a raise, promotion or may have to suffer negative consequences. The main goal of all appraisals is to evaluate and analyze whether a worker has the skills and qualities needed for effectively doing his job. Globally various systems for evaluation of employee performance are used, such as, 'Management by Objectives', which includes comparing set goals and standards for a worker with the actual contribution and productivity of an employee. '360 Degree Appraisal' is another method, in which an employee is judged and evaluated by everyone working around, from his manager to co-workers, friends, and even consumers and suppliers. The appraisal system is also operational for the teachers serving in the public schools of Pakistan.

The first and the fundamental purpose of performance appraisal is to assess the performance of the staff, periodically (Iqbal, Akbar, \& Budhwar, 2015; deNisi \& Murphy, 2017), whereas Melnyk, Bititci, Platts, Tobias and Andersen (2014) asserted that the purpose of annual teacher evaluation or appraisal is to analyze the gap between the desired and the actual performance of the staff. The teacher performance evaluation system serves two simultaneous purposes, accountability and improvement. The ambiguities and tensions produced thus are recognized internationally (Shabbir, Khalid, Bakhsh, Mohsin, Rasool, \& Mohsin, 2016); therefore, Farrell (2016) recommended that the balance between accountability and alignment is a contemporary issue which has yet to be resolved, even more so in Pakistan.

Since performance appraisal may carry serious implications for an employee (Reddy, Dudek, Peters, Alperin, Kettler \& Kurz, 2018), the way it is conducted cannot be ignored. It appears

\footnotetext{
* University of Management and Technology Lahore Email: mnadeem439@gmail.com

** University of Management and Technology Lahore Email: seema.arif@umt.edu.pk

*** FMDRC Lahore Email: drnaeemuvas@ gmail.com
} 
mandatory that the supervisor or manager conducting any appraisal must be familiar with its dynamics and outcomes. Moreover, he/she should be able to interpret the evidence and make quality decisions for the future professional development of the employee (Ahmad \& Azman, 2014). The appraisal system comprises of both written and oral elements (Kim and Holzer, 2016) to evaluate the job performance according to a pre-decided criterion (Warokka, Gallato, Thamendren, \& Moorthy, 2012)

School is an organization that works as an open social system made up of people who manage that system and steer it in the right direction (Luthans \& Youssef, 2017). Teachers are chief actors in school and constitute the core of the educational system (Chetty, Friedman, \& Rockoff, 2014). According to Taut and Sun (2014), the role of the principal is critical in teachers' appraisal; they are responsible for guiding teachers about improving their performance by practical feedback. Tobin (2014) indicated that principals, using their leadership capabilities, motivate staff to generate a positive response towards PAS.

\section{Statement of the Research Problem}

Currently, the performance of public higher secondary school teachers is keenly observed by school management since there is a decreasing trend of enrolment in public schools. Continuous decline of student achievement of public secondary schools in comparison with private schools has raised the brows of central authorities and board members. Therefore, it is the need of the hour to probe the current performance appraisal system and check its effectiveness in public schools to point out the problem areas.

This interdisciplinary research, covering the fields of teacher education, organizational psychology, and Human Resource Management (HRM), was conducted to record the understanding of the stakeholders of PAS - the principals, teachers, and administrators. It is assumed that the accurate evaluation of performance amplifies workers' productivity motivating them to work sincerely. The PAS adopted by the Education Department of Punjab has its strengths and weaknesses; we shall consider both as perceived by the stakeholders.

\section{Objectives of the Study}

Following were the objectives of the study:

1. To find the perceptions of school stakeholders (administrators, principals, and subject specialists) about PAS as it is used for the appraisal of public higher secondary school teachers of Punjab.

2. To investigate the strengths and weaknesses of PAS in public higher secondary schools of the Punjab.

\section{Literature Review}

Performance appraisal entails the purpose of helping the management towards the implementation of control in the organization (deNisi \& Smith, 2014) and strengthening the communication and working relationship among employees, seniors, and management (Deepa, Palaniswamy, \& Kuppusamy, 2014). Buckingham and Goodall (2015) highlighted that performance appraisal provides clarity of role to employees for the responsibilities and expectations of the workplace. Along with comparing the actual and desired performance, appraisal results act as feedback for future goal setting for improvement and enhanced performance (Landy, Zedeck, \& Cleveland, 2017). However, Pulakos, Hanson, Arad, and Moye (2015) indicated that without proper training to conduct PAS, its desired outcomes could not be reached.

The meaning of awareness is to guide people about a specific thing (Mertens \& Wilson, 2018). In the context of PAS, the school principals must guide teachers about the basics of teacher appraisal and its conduction (Kanto, Ahmad, Talib, \& Tiro, 2014). The policies, duration, criteria, and other aspects must be elaborated to teachers for guiding them during PAS. Hyun and Sajjad (2018) outlined that the public schools in Pakistan commonly use a summative evaluation system to appraise teacher performance of teachers, but regular monitoring has been missing for a long time. While assessing the performance of teachers, it has been recommended by many scholars that it should be carried out unbiased to obtain the real results of the assessment (Kowsalya \& Karthikeyan, 2016).

According to Akin, Yildirim, and Goodwin (2016), education is defined concerning the quality of teaching, and it depends on the high performance of teachers in the respective subject. The study evaluates the procedures and assessment of teachers' performance in terms of providing quality education to students, which plays a vital role in improving the educational culture (Deal \& Peterson, 
2016). Previous research has identified that institutes unable to initiate an appropriate appraisal system get a compromised teacher performance (Huber \& Skedsmo, 2016). It is promising that the present system of performance appraisal is much broader and enjoins the self-appraisal system (János, 1999). The filling of Performa's for the self-appraisal takes place after group discussions with peers and seniors. The report related to job performance is disclosed to the concerned person only; this is how privacy and confidentiality are maintained. Specifically, it is ensured that the process of appraisal remains fair and transparent and no miscommunication occurs spoiling the credibility of the appraiser and the process.

The teacher performance evaluation system serves two simultaneous purposes, that is, accountability and improvement. The ambiguities and tensions produced by the above mentioned two functions have merged and have been recognized internationally (Shabbir et al., 2016); therefore, Farrell (2016) recommended that the balance between accountability and alignment is a contemporary issue which has yet to be resolved, even more so in Pakistan.

A principal may play multiple roles during the conduction of PAS. Dee and Wyckoff (2015) intimated that school principals set clear expectations, personally observe the monitoring processes, and offer opportunities for professional development, suiting the needs of individual teachers. Furthermore, school principals systematically build the system's capacity to carry out PAS. Besides, some of the roles played by leaders in school while implementing PAS include the procurement and distribution of resources, encouraging and supporting teachers, fortifying the rules, and exhibiting personal interest in the process of appraisal and professional development of staff (Elliott, 2015). This research aims to find out how this responsibility of conducting PAS is shared among the district administrators and school principals.

Avalos (2011) pointed out that the school principals neglect to prepare teacher portfolios, keeping the teacher performance record over a longer time, thus cannot make a comparative evaluation of their performance over time. These isolated sets of performance measurements do not help in formulating any future strategy for the sustainable development of school or staff. Neither it can be estimated how a change in performance would be attributed? It was an outcome of teachers' effort, or participation in some courses, workshops, or training programs (Anderson, 2019). Thus, the record-keeping of a school principal could be much more beneficial.

Al-Jammal (2012) identified the mandatory skills to be acquired by the school principals to conduct performance appraisal. He (Jammal) highlighted that school principals are not abreast with the modern appraisal techniques, and conduct appraisal using traditional methods. Similar is the case in Pakistan, where school principals are not much enthusiastic in learning new methods and techniques of the appraisal to do justice with the purpose and mission of PAS (Shakir \& Adeeb, 2014); they take it as a compliance order to another routinized duty (Nadeem, Arif \& Asghar, 2019). No wonder why the researchers (Nadeem et al.) recommended an urgent action for principals to transform their knowledge, attitudes, and practices to conduct Performance appraisal.

Brandon, Hollweck, Donlevy, and Whalen (2018) proclaimed that effective supervision and evaluation are part of a long career continuum of practice that fosters teacher growth while ensuring quality teaching. Teacher appraisal is often conducted as a mechanical obligation involving technical expertise but missing the spirit of professional development (Firestone, 2014). However, it is noted by Tuyten and Devos (2014) that a regular teacher appraisal may inspire teachers to assume professional learning activities much seriously when they render feedback as beneficial. Tuyten and Devos (2017) emphasize teachers' involvement in collaborative activities during the appraisal to leave a positive impact upon evaluation and its outcomes. Hallinger (2011) expounded that school principals who assume the role of 'leaders for learning' demonstrate the ability to adjust their style suiting the needs of a specific situation.

\section{Method and Materials}

The study was conducted in the interpretive paradigm using phenomenology as an approach towards examining the problem. The constructivist epistemological lens was useful in recording 'the lived experiences' of higher secondary school teachers, principals, and district administration about the conduction of PAS. This design has been particularly useful because previously a little research on the topic under discussion was available in the Pakistani context, and in-depth exploration of the ideas of the stakeholders about PAS was generated this way (Creswell, 2013). The study was a follow up of a survey conducted on the topic (Nadeem et al., 2019). Nine hundred teachers and 90 school 
principals were part of the survey research. For this part of the research, the researchers used qualitative techniques for conduction and analysis of data. Out of nine districts selected for the survey, five opted for structured interviews; the purpose was triangulation. The researchers used criterionbased purposive sampling while the population of the research was participants of survey research. It was ensured that all districts are represented across the district school rankings regarding the quality performance, two high performing districts, two average performing districts, and one low performing district was selected who agreed to be part of the study. Data were taken from 35 participants included five district administrators, ten principals, and 20 teachers of the selected higher secondary schools. It was further ensured that one principal each from boys and girl's schools and at least two teachers (male and female) from each school were selected. Fig 1 below describes the population size.

\section{Inclusion Criterion}

School principals, teachers, and administrators were selected who had been serving for more than one year on the post at the time of data collection. The school principals and administrators must have conducted PAS at least once in professional life. School teachers must have filled and submitted PAS at least once in professional life.

\section{Exclusion Criterion}

All those who did not fulfil the above criterion were not part of the study.

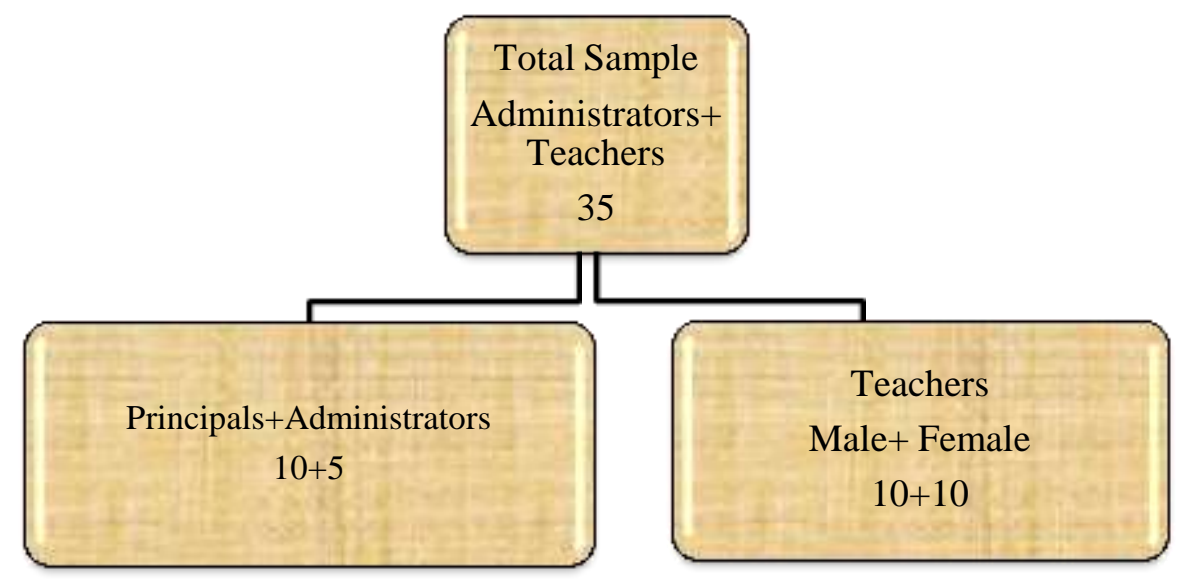

\section{Instrumentation}

Figure 1 Qualitative Sample Size

Self-constructed protocol for structured interviews was used for this particular purpose. Two protocols were constructed, one for higher secondary school teachers for a focus group; it comprised ten items. The other protocol was for the structured interviews with the district administrators and higher secondary school principals; it comprised 16 items. Each of the protocols consisted of two parts; one collected demographic information, and the other aimed at getting answers to the research questions. The interview protocols were developed for this study by using different sources, including, the results of survey research and literature review as the context. The probes were focused on three areas; strengths and weaknesses of the PAS, issues faced during the conduction of appraisal, and improvements needed for the PAS.

It is essential to ensure the internal validity and reliability of the research process in any qualitative design, whereas generalizability was not much of the concern (Patton, 2002). Triangulation of sources was ensured as data was gathered from district administration, school principals, and teachers. Furthermore, a pilot study was conducted, as well. Through the pilot study, the researcher checked the comprehensiveness of the interview protocol to overcome any possible difficulties which may arise during the interviews. The researcher interviewed 5 participants from a district (which was not included in the final data); no issues were recognized in the pilot study; hence no changes were made to the protocols, and researchers proceeded for further data collection.

\section{Methods for Data Collection}

Interviews are purposeful conversation or exchange of ideas about a predefined subject (Kvale, 2008; Brinkmann, 2014). The study was cross-sectional, and interviews helped the researchers to get extensive data in a short time. Interviews allow the researcher to use multi-sensory channels: verbal, 
non-verbal, spoken, and heard (Cohen, Manion, \& Morrison, 2018) during focus groups and interviews. King, Cassell, and Symon (2004) stated that realist, phenomenological, and constructionist were three different approaches of interviews. The researcher used the realist approach in this study to gain participants' real representation of their experiences of PAS. These interviews were more structured in nature than phenomenological or social constructionist interviews.

During this process, descriptions of the interviewees were gathered regarding issues related to the performance appraisal system used for public school teachers to gauge their performance (King et al., 2004). Interviews are of various forms; Merriam (2019) described three different forms of interviews: highly structured, semi-structured, or unstructured. In this study, the researcher used structured interviews to collect data. A structured interview is a valuable explanatory tool and involves a set of predetermined but open-ended questions. Interviews can be individual, one to one, or group discussions focused on a particular research problem. The researcher used one to one, structured interviews with higher secondary school principals and administrators, while used focus group techniques with higher secondary school teachers. Tharenou, Donohue, and Cooper (2007) outlined that specific attitudes and feelings of a consistent group can be investigated via focus groups. Therefore, focus groups were carried out in each district with five school teachers (both male and female) to probe deep into thoughts of higher secondary school teachers to their understanding of PAS, and its impact on their careers. The flexible nature of the technique made it easier to uncover complex ideas (Belzile \& Öberg, 2012) related to the phenomenon PAS and its conduction once a year.

The interviews were conducted as 'an interchange of views' over a cup of tea, providing an informal and relaxed air to the participants. Interviews were structured so that unpredictability could be avoided, and precise information is collected on the phenomenon. However, interviews varied in content, depth, and length; ranging from 45 minutes 60 minutes, whereas focus group time ranged from 80 to 100 minutes. The participants allowed us to record their interviews, and the recording was repeatedly used in transcribing the interviews, and further interpretive analysis.

\section{Data Analysis}

In this section demographic distribution of data is presented followed by the thematic analysis of the data collected from interviews and focus groups.

Table 1

Demographic Distribution of Data

\begin{tabular}{lcccc}
\hline Gender & Administrators & Principals & Teachers & $\%$ \\
\hline Male & 3 & 5 & 10 & 51.0 \\
Females & 2 & 5 & 10 & 49.0 \\
Total & 5 & 10 & 20 & 100.0 \\
\hline Age & & & & \\
\hline 30 below & 0 & 0 & 2 & 6.00 \\
$30-35$ & 0 & 0 & 4 & 11.00 \\
$35-40$ & 0 & 3 & 5 & 23.00 \\
$40-50$ & 2 & 5 & 6 & 34.00 \\
$50-60$ & 3 & 2 & 3 & 26.00 \\
Total & 5 & 10 & 20 & 100.00 \\
\hline Qualification & & & & \\
\hline Masters & 0 & 4 & 12 & 54.00 \\
MPhil & 2 & 4 & 7 & 29.00 \\
PhD & 3 & 2 & 1 & 17.00 \\
Total & 10 & 20 & 100.0 \\
\hline Experience & 5 & & & \\
\hline $1-5$ & & 0 & 5 & 14.00 \\
$6-10$ & 0 & 2 & 4 & 26.00 \\
$11-15$ & 1 & 2 & 5 & 43.00 \\
16 or more & 2 & 6 & 6 & 100.0 \\
Total & 2 & 10 & 20 & \\
\hline
\end{tabular}

Thematic Analysis

Guidelines for thematic analysis provided by Meriam (1998) were used to screen, transcribe and organize interview data into themes. Using these guidelines, the researchers ensured that the derived 7 
themes were: 1) aligned with research objectives, 2) generated in-depth thick descriptions, 3) welldifferentiated, 4) addressed sensitively a particular topic, and 5) theoretically compatible. The categorization of data into themes helped the researchers to access deep underlying meanings related to the phenomenon, performance appraisal system (PAS) as conducted yearly in higher secondary schools of Punjab (Miles \& Huberman 1994; Richards \& Hemphill, 2018), hence, fulfilling all objectives of this study. Researchers performed the thematic analysis manually while treating each other as 'a critical partner.' Researchers read the transcribed data multiple times, taking notes, crosschecking each other's descriptions; hence following the 'inductive-deductive way', the researchers reached an in-depth understanding of the phenomenon performance appraisal system as experienced by its key stakeholders. The following themes have been derived through careful analysis derived from the data obtained from district administration, higher secondary school principals, and teachers.

\section{Awareness about the PAS}

Responding to the inquiry about the reasons for conducting performance appraisal, all principals and district administrators agreed that PAS is an evaluation process. Most of the principals and administrators committed that their teachers have sufficient knowledge and experience to go through PAS. Major reasons for conducting PAS included: giving feedback to employees, correcting deficiencies at work, and providing training and development. One of the principals said that PAS is a time-wasting process, and it creates bias among the teachers, whereas school teachers demanded that PAS should be made in consultation with teachers and principals. Similarly, the majority of the teachers described staff appraisal as an evaluation process. Most of the teachers remarked that excellent student results, effective classroom management, teaching quality comprise teacher performance and can be attributed to 'fair evaluation.'

\section{Foundation of PAS}

Regarding the identification of the factors constructing the foundation of PAS, most of the principals recounted that evaluation of teachers' subject knowledge, classroom management, and the quality of teaching is the significant factor laying the foundation of the conduction of PAS. Few of them opined that classroom management, punctuality, and quality teaching are the key factors. On the other hand, district administrators said that punctuality, classroom management, and quality of teaching are the most critical factors constructing the foundation of PAS. Few of them said that classroom management and punctuality are the main factors to be checked during PAS.

\section{Management Support during Implementation of PAS}

Responding to the idea of management support to teachers during PAS, many principals affirmed that the teachers need support and they must be provided for it; however, few of them were of the view that "teachers need constant supervision during PAS." Similarly, another difference of view was observed; more than half of the principals advocated that PAS should be made in consultation with teachers and principals, while others were against it; they considered that teachers must follow the instructions as they are subordinates. Some principals identified that some of their teachers "need regular feedback during the conduction of PAS." The district administrators, however, stressed that PAS is a state affair needing full compliance of the whole staff; everyone must do their duty according to guidelines provided. The objective of accountability cannot be compromised for better future outcomes for schools. One of the administrators said that PAS is a continuous process and proper knowledge and experience are needed for its implementation; therefore, the school principals must continuously update themselves. Most of the teachers said that teachers need careful handling and support during PAS; "we must not be treated as suspects of a crime." implementation. School management and the district staff should be respectful and motivate the teachers for their active participation.

\section{Conduction of PAS}

Responding to teacher involvement in PAS, most of the principals replied that they follow established performance standards; many teachers work in groups for collective benefit. Few principals related that teachers not only work in teams but also maintain standards that communicate required expectations, measure actual performance, and discussion of results, and decision-making for the future. They declared that PAS is a useful tool to map further training and professional development.

District administrators also agreed that teachers get involved in the processes quoted above; they affirmed that they promote teamwork among staff and teachers. Most of the teachers remarked 
that PAS would be successful if the results keep informing us about our strengths and weaknesses as teachers; they added constructive feedback that motivates them to reflect over their performance and take active measures to perform better.

\section{Satisfaction with PAS}

Referring to the satisfying outcomes of PAS, a mutual consensus was achieved among the responses of the three stakeholders, that the chief outcome of PAS would be a comprehensive plan of teachers' professional development at the district level. Most of the principals stated that their teachers need training for innovative teaching methods, especially for lesson planning and assessment. Few of the principals asserted that recognizing teachers' efforts for improvement and awarding with incentives shall increase teacher satisfaction. On the other hand, administrators remarked that the teachers' participation in the planning and implementation of PAS would be more satisfying for the teachers.

Likewise, most of the teachers said that PAS is a continuous process and provides feedback to employees to check their performance. Few of the teachers said that teachers should be admired and rewarded with incentives for their job satisfaction. It also helps teachers to judge their strengths and weaknesses for further improvement. It provides them with the opportunity to enhance the prospects of their promotion and career advancement. One of the teachers said that staff appraisal is an effective process, and its results must be used to set future goals for effective teaching and coordination.

\section{Dissatisfaction with PAS}

Responding to the question about dissatisfying factors related to the conduction of PAS, most of the principals dissented that their teachers show resistance toward change. There could be many reasons for the resistance: half of the principals observed that their teachers have sufficient knowledge and experience, but they have been ignored in the planning and decision-making process, while few others stated that teachers are not well motivated due to lack of incentives. On the other hand, district administrators believed that employees lack the understanding of the value and worth of PAS.

Most of the teachers said that PAS does not accurately measure teacher competence, and teacher quality, adding that PAS was an imported tool, therefore, not as culturally relevant. They drew attention to the fact that PAS does not fit in the context of the Pakistani school education system as practiced in rural areas of Punjab. Few of them complained that teachers were ignored in the planning and executing of PAS. One of them pointed out that indicators of PAS do not align with the professional standards for teachers outlined by the government of Punjab.

Regarding other negative impacts of PAS, most of the teachers recounted that PAS increased their anxiety, left them frustrated, and made them think about leaving their job. Many teachers contended that on the job training, and a comprehensive set of workshops is required to make teachers comprehend the appraisal system to make it an efficient and acceptable system for accountability. One teacher remarked the process does not leave any sense of appreciation to me.

\section{Need for Improvements in the conduction of PAS}

Referring to the needed improvements in the conduction of PAS, most of the principals remarked that providing regular feedback to teachers regarding their performance works best in the execution of PAS. Some of the principals wanted to hold regular meetings to assess school needs for PAS implementation. Whereas, few of the principals suggested that teachers' opinions must be incorporated in problem-solving during the conduction of PAS. Leadership facilitation was rendered the best approach for successful PAS implementation. Most of the administrators noted that proper feedback is necessary for the teachers during the PAS.

It was pointed out by teachers that teacher appraisal is dealt with as an isolated activity occurring once a year by the management. Moreover, school principals focus more on individual weaknesses and strengths of teachers rather than speaking about teachers' school-wide role in creating partnerships, thus contributing to whole school improvement.

\section{Discussion}

In Pakistan, an annual confidential report (ACR) was used in the past to evaluate the performance of teachers, which was written by the school head every year, comprising the accomplishments or weakness of the teachers throughout the year. Now performance evaluation report (PER) is used for this purpose. The results show that appraisal is conducted in traditional spirit and accounts for an isolated activity. Although the teacher performance is measured against National Professional Standards (Shakir \& Adeeb, 2014) and schools are considered self-responsible to analyze the 
students' behavior, achievements, and qualities for decision making (Chaki, Sazal, Barua, Hossain, \& Mohammad, 2019). But PAS does not follow the true spirit of three sixty-degree appraisal as the feedback of most important stakeholders, the students, and parents is not collected (Zins \& Elias, 2007).

The study results indicate that awareness of PAS improves the satisfaction level of teachers. According to the opinion of the teachers' management support is the real challenge for the PAS process. Teachers perceived that on the job training and a comprehensive workshop are required for them to comprehend the system. Overall, principals should value the opinions and suggestions of teachers. Results revealed that the current study described the results of a study conducted by Iqbal (2013) appraisal system in schools. In public schools, most teachers are working permanently, and despite large classes, their performance is good. They manage and plan their lessons better way. Derrington and Campbell (2018) reiterated that principals exercise their instructional leadership values and perspectives by working through and adapting to the policy and then exercising their independent judgment to meet the policy's objectives outcomes.

Khan and Suhag (2019) identified certain practices to be ensured by the school management during appraisal to improve the current performance appraisal system for teachers. Performance appraisal should not only be conducted to take promotional decisions for teachers, rather it should focus on improvements in teachers' performance and to develop teachers' professional careers. A 360-degree feedback system should be the base of the appraisal system. Feedback should be taken from colleagues of the teacher, administrative staff, and from his students.

\section{Conclusion}

The results of the study show that PAS is an evaluation process, and the principals and teachers have enough knowledge and experience to implement the PAS. It is a positive activity that must be continued; however, the procedure needs improvement. Administrators and principals remarked that teachers should be appraised and motivated for their satisfaction. The discussion on themes has further revealed that all the factors are in harmony with PAS except teachers' dissatisfaction with the outcomes of PAS. All stakeholders, district administration, higher secondary school principals and teachers, agreed that the process needed improvement; PAS should be planned and conducted with the consultation of teachers motivating them for further improvement.

\section{Suggestions for Improvement}

1. A school principal should keep an eye on the individual progress of teachers and provide all the facilities which they need, including guidelines to follow PAS and workshop/ training needed for the awareness of PAS.

2. PAS, which is to be implemented, should be made in consultation with teachers and SMART goals for its implementation must be set with consensus.

3. Harmony between teachers' and principal's work is the need of the hour. There should be coordination and a professional relationship between them. The principals should hold regular meetings with their staff for successful PAS implementation.

4. Refresher courses should be planned according to the changes in the skills required by the new performance scale. The awareness of PAS improves the satisfaction level of teachers.

5. The reinforcement plan and the use of reward and punishment judiciously motivate the staff and keep the teachers accountable for their performance.

6. Management support is the real challenge for PAS. Without the necessary awareness of PAS, teacher effectiveness cannot be measured appropriately. The principals must promote teamwork and appreciate and reward teams rather than individuals, so that peer learning may be enhanced.

7. In the view of administrators, teachers should not only participate in PAS development, and their opinions must be sought during its implementation and post-implementation for the sake of future improvements.

8. Needs analysis must be conducted for providing training in leadership, and motivational skills

References and performance must be measured based on the training taken by the staff and principals.

Ahmad, R., \& Azman N. A. (2004). Performance appraisal decision in Malaysian public service. International Journal of Public Sector Management, 17(1), 48-64. 
Akin, S., Yildirim, A., \& Goodwin, A. L. (2016). Classroom management through the eyes of elementary teachers in Turkey: A phenomenological study. Educational Sciences: Theory and Practice, 16(3), 771-797.

Al-Jammal, K. (2012). Staff's performance appraisal: The case of Lebanese private school principals through teachers' perception. International Journal of Management Research \& Review, 5(10), 744-776.

Anderson, D. L. (2019). Organization development: The process of leading organizational change. Thousand Oaks, CA: SAGE.

Avalos, B. (2011). Teacher professional development in teaching and teacher education over ten years. Teaching and Teacher Education, 27(1), 10-20.

Belzile, A. J. \& Öberg, G. (2012), Where to begin? Grappling with how to use participant inter-action in focus group design. Qualitative Research, 12(4), 459-472.

Brandon, J., Hollweck, T., Donlevy, J. K., \& Whalen, C. (2018). Teacher supervision and evaluation challenges: Canadian perspectives on overall instructional leadership. Teachers and Teaching, 24(3), 263-280.

Brinkmann, S. (2014). Interview. In T. Teo (Ed.), Encyclopedia of critical psychology (pp. 10081010). NY: Springer.

Buckingham, M., \& Goodall, A. (2015). Reinventing performance management. Harvard Business Review, 93(4), 40-50.

Chaki, P. K., Sazal, M. M. H., Barua, B., Hossain, M. S., \& Mohammad, K. S. (2019). An approach of teachers' quality improvement by analyzing teaching evaluations data. Paper presented at the 2019 Second International Conference on Advanced Computational and Communication Paradigms (ICACCP). Sikkim Manipal Institute of Technology, Sikkim, India.

Cohen, L., Manion, L., \& Morrison, K. (2018). Research methods in education. London: Routledge

Creswell, J. (2013). Qualitative inquiry and research design: Five different approaches. Thousand Oaks: CA: SAGE.

Deal, T. E., \& Peterson, K. D. (2016). Shaping school culture. NY: John Wiley \& Sons

Dee, T. S., \& Wyckoff, J. (2015). Incentives, selection, and teacher performance: Evidence from impact. Journal of Policy Analysis and Management, 34(2), 267-297.

Deepa, E., Palaniswamy, R., \& Kuppusamy, S. (2014). Effect of performance appraisal system in organizational commitment, job satisfaction and productivity. Journal of Contemporary Management Research, 8(1), 72-81.

Derrington, M. L., \& Campbell, J. W. (2018). High-stakes teacher evaluation policy: US principals' perspectives and variations in practice. Teachers and Teaching, 24(3), 246-262.

deNisi, A. S., \& Murphy, K. R. (2017). Performance appraisal and performance management: 100 years of progress? Journal of Applied Psychology, 102(3), 421-433.

deNisi, A., \& Smith, C. E. (2014). Performance appraisal, performance management, and firm-level performance: A review, a proposed model, and new directions for future research. The Academy of Management Annals, 8(1), 127-179.

Elliott, K. (2015). Teacher Performance Appraisal: More about performance or development? Australian Journal of Teacher Education, 40(9), 102-116.

Farrell, T. S. (2016). Anniversary article: The practices of encouraging TESOL teachers to engage in reflective practice: An appraisal of recent research contributions. Language Teaching Research, 20(2), 223-247.

Firestone, W. A. (2014). Teacher evaluation policy and conflicting theories of motivation. Educational Researcher, 43, 100-107.

Hallinger, P. (2011). Leadership for learning: Lessons from 40 years of empirical research. Journal of Educational Administration, 49, 125-142.

Huber, S. G., \&Skedsmo, G. (2016). Teacher evaluation-accountability and improving teaching practices. Educational Assessment, Evaluation and Accountability, 28(2), 105-109.

Hyun, R. J., \& Sajjad, S. (2018). Quality of teachers' performance evaluation in public and private secondary schools of Karachi, Pakistan. Pakistan Journal of Education, 35(2), 157-174.

Iqbal, K. (2013). Determinants of organizational justice and its impact on job satisfaction. A Pakistan base survey. International Review of Management and Business Research, 2(1), 48-56. 
Iqbal, M. Z., Akbar, S., \& Budhwar, P. (2015). Effectiveness of performance appraisal: An integrated framework. International Journal of Management Reviews, 17(4), 510-533.

János, S. (1999). A minöség kora: Bevezetés az iskolai minőségbiztositás gyakorlatába. Budapest: Raabe Klett.

Kanto, K., Ahmad, M. A., Talib, S. B., \& Tiro, M. A. (2014). The influence of certification toward work motivation, job satisfaction and performance of state high school guidance and counseling teacher in South Sulawesi. International Journal of Science and Technology Research, 3(8), 386-394.

Kowsalya, P., \& Karthikeyan, R. (2016). A study on effectiveness of performance appraisal in foam matings India Ltd Alapuzha. International Journal of Research in Social Sciences, 6(6), 316331.

Kvale, S. (2008). Doing interviews. Thousand Oaks, CA: SAGE.

Kvale, S., \& Brinkmann, S. (2009). Interviews: Learning the craft of qualitative research interviewing. Thousand Oaks, CA: SAGE.

Khan, H. H., \& Suhag, A. K. (2019). Performance and Appraisal Framework for Untrained Teachers Working in Private Schools of Karachi. International E-Journal of Advances in Education, 5(13), 58-65.

Kim, T., \& Holzer, M. (2016). Public employees and performance appraisal: A study of antecedents to employees' perception of the process. Review of Public Personnel Administration, 36(1), 31-56.

King, N., Cassell, C., \& Symon, G. (2004). Using templates in the thematic analysis of text. Essential guide to qualitative methods in organizational research, 2, 256-70.

Landy, F., Zedeck, S., \& Cleveland, J. (2017). Performance measurement and theory. NY; Routledge.

Leithwood, K. (2016). Department-head leadership for school improvement. Leadership and Policy in Schools, 15(2), 117-140.

Luthans, F., \& Youssef-Morgan, C. M. (2017). Psychological capital: An evidence-based positive approach. Annual Review of Organizational Psychology and Organizational Behavior, 4, 339-366.

Melnyk, S. A., Bititci, U., Platts, K., Tobias, J., \& Andersen, B. (2014). Is performance measurement and management fit for the future? Management Accounting Research, 25(2), 173-186.

Merriam, S. B. (2019). How Context Shapes the Design and Implementation of a Qualitative Study. In S. B. Merriam \& R. S. Grenier, (Eds.). Qualitative research in practice: Examples for discussion and analysis (p. 54-83). NY: John Wiley \& Sons.

Mertens, D. M., \& Wilson, A. T. (2018). Program evaluation theory and practice. New York: Guilford.

Miles, M. B., Huberman, A. M., Huberman, M. A., \& Huberman, M. (1994). Qualitative data analysis: An expanded sourcebook. Thousand Oaks, CA: SAGE

Nadeem, M., Arif, S. \& Asghar, Z. (2019). Effectiveness of the teacher appraisal system in public higher secondary schools of Punjab (Pakistan). Global Regional Review, 4(1), $194-208$.

Patton, M. Q. (2002). Two decades of developments in qualitative inquiry: A personal, experiential perspective. Qualitative social work, 1(3), 261-283.

Pulakos, E. D., Hanson, R. M., Arad, S., \& Moye, N. (2015). Performance management can be fixed: An on-the-job experiential learning approach for complex behavior change. Industrial and Organizational Psychology, 8(1), 51-76.

Rasheed, M. I., Yousaf, H. D. A. S., \& Noor, A. (2011). A critical analysis of performance appraisal system for teachers in public sector universities of Pakistan: A case study of the Islamia University of Bahawalpur (IUB). African Journal of Business Management, 5(9), 3735-3744.

Reddy, L. A., Dudek, C. M., Peters, S., Alperin, A., Kettler, R. J., \& Kurz, A. (2018). Teachers' and school administrators' attitudes and beliefs of teacher evaluation: a preliminary investigation of high poverty school districts. Educational Assessment, Evaluation and Accountability, 30(1), 47-70.

Richards, K. A. R., \& Hemphill, M. A. (2018). A practical guide to collaborative qualitative data analysis. Journal of Teaching in Physical Education, 37(2), 225-231.

Sandholtz, J. H., \& Scribner, S. P. (2006). The paradox of administrative control in fostering teacher professional development. Teaching and Teacher Education, 22, 1104-1117. 
Shabbir, M., Khalid, M. I., Bakhsh, K., Mohsin, M. N., Rasool, S., \& Mohsin, M. S. (2016). Improving professional development system through quality assurance practices in the universities of Pakistan. International Education Studies, 9(1), 141-147.

Shakir, M., \& Adeeb, A. (2014). Performance appraisal: An evaluation of teachers 'competencies based on national professional standards in Pakistan. International Review of Social Science, 2(12), 532-539.

Tharenou, P., Donohue, R., \& Cooper, P. (2007). Management research methods. London: Cambridge University Press.

Tobin, J. (2014). Management and Leadership Issues for School Building Leaders. International Journal of Educational Leadership Preparation, 9(1), 21-35.

Tuytens, M., \& Devos, G. (2014). How to activate teachers through teacher evaluation? School Effectiveness and School Improvement, 25(4), 509-530.

Tuytens, M., \& Devos, G. (2017). The role of feedback from the school leader during teacher evaluation for teacher and school improvement. Teachers and Teaching, 23(1), 6-24.

Warokka, A., Gallato, C. G., Thamendren, A., \& Moorthy, L. (2012). Organizational justice in performance appraisal system and work performance: evidence from an emerging market. Journal of Human Resources Management Research, 1, 1-18.

Zins, J. E., \& Elias, M. J. (2007). Social and emotional learning: Promoting the development of all students. Journal of Educational and Psychological Consultation, 17(2-3), 233-255. 